ORIGINAL ARTICLE

\title{
Validation of specific inhalation challenge for the diagnosis of occupational asthma due to persulphate salts
}

\author{
X Muñoz, M J Cruz, R Orriols, F Torres, M Espuga, F Morell
}

Occup Environ Med 2004;61:861-866. doi: 10.1136/oem.2004.013177

See end of article for authors' affiliations .....................

Correspondence to: Dr X Muñoz, Servicio de Pneumologia, Hospital General Vall d'Hebron, Passeig Vall d'Hebron, 119, 08035 Barcelona, Spain; xmunoz@vhebron. net

Accepted 16 June 2004

\begin{abstract}
Background: The significant value of tests used to certify the diagnosis of occupational asthma due to persulphate salts remains uncertain.

Aims: To validate the specific inhalation challenge (SIC) test for the diagnosis of occupational asthma. Methods: Eight patients with occupational asthma due to persulphate salts, eight patients with bronchial asthma who were never exposed to persulphate salts, and ten healthy subjects were studied. Clinical history taking, spirometry, bronchial challenge with methacholine, skin prick testing to common inhalant allergens and persulphate salts, total $\operatorname{lgE}$ levels, and SIC to potassium persulphate were carried out in all subjects. The SIC used increasing concentrations of potassium persulphate $(5,10,15$, and $30 \mathrm{~g})$ mixed with $150 \mathrm{~g}$ of lactose. Patients tipped the mixture from one tray to another at a distance of $30 \mathrm{~cm}$ from the face for 10 minutes in a challenge booth.

Results: The SIC was positive in all subjects with persulphate induced asthma and in one patient with bronchial asthma who had never been exposed to persulphate salts. Sensitivity was $100 \% 195 \% \mathrm{Cl} 67.6$ to $100)$ and specificity was $87.5 \%(95 \% \mathrm{Cl} 52.9-97.8)$ when patients with occupational asthma due to persulphate salts were compared with those with bronchial asthma never exposed to persulphate salts. Conclusions: SIC to persulphate salts performed according to the protocol described appears to be useful for the diagnosis of occupational asthma secondary to inhalation of this substance.
\end{abstract}

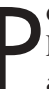
ersulphate salts, which are widely used constituents of hair bleaches, have been shown to cause occupational asthma (OA) in hairdressers and chemical workers. ${ }^{12}$ The first cases of OA due to persulphate salts were described 30 years ago, ${ }^{3-5}$ and persulphate induced asthma may now represent up to $4 \%$ of all OA cases. ${ }^{6}$ Nevertheless, the mechanism by which persulphate salts induce asthma, the risk factors for developing this condition, and the value of tests for diagnosing asthma due to this substance remain uncertain.

The largest series of patients with OA due to persulphate salts published recently focuses on the importance of specific inhalation challenge (SIC) to establish the diagnosis. ${ }^{1}$ The clinical history often does not suffice to reach a definite diagnosis of $\mathrm{OA}^{7}$ immunological tests have low sensitivity and specificity for diagnosing OA due to persulphate salts, ${ }^{18}$ and doubts exist as to the usefulness of peak expiratory flow study in these patients. ${ }^{12}$ Moreover, the population most often exposed to persulphate salts are hairdressers, who may also be in contact with other agents that can cause OA, such as henna and paraphenylenediamine.$^{10}$ Hence, the SIC seems indicated to determine the exact cause of $\mathrm{OA}$ in these patients.

There are few studies in which SIC has been performed to diagnose OA due to persulphate salts, and they have used several different methods. Some authors carried out the test by attempting to reproduce the conditions in the workplace, $^{34}$ others by aerosolising potassium persulphate extract, ${ }^{11} 12$ and others by tipping a mixture of bleach powder $^{213}$ or potassium persulphate ${ }^{1}$ and lactose from one tray to another. Furthermore, since persulphate salts possess considerable oxidant properties, ${ }^{14}$ exposure to sufficient levels might trigger asthma through an irritative mechanism. It is important to rule out this factor to avoid false positives during SIC and an erroneous diagnosis.

The aims of the present study were to describe a method for performing SIC in patients with suspected OA due to persulphate salts, and to study the sensitivity and specificity indices obtained by comparing SIC results in these patients with those in patients with bronchial asthma who had never been exposed to persulphate salts.

\section{METHODS}

\section{Study population}

The study population included eight women (mean age 37 years; range 23-52 years) with occupational asthma due to persulphate salts (group A), diagnosed at our occupational respiratory disease unit between 1997 and 2002. The diagnosis had been made following the criteria proposed by Chan-Yeung and Malo ${ }^{15}$ for occupational asthma, based on clinical history (including exhaustive occupational history), lung function testing (including spirometry, bronchodilator test, non-specific challenge test, and peak flow study) and immunological testing. Three patients were employed in a cosmetics factory where they mixed persulphate salts with other chemical agents to produce hair bleaches, and five patients worked with dyes in hairdressing salons. In the latter cases, the hair bleaches containing persulphate salts were supplied to the salon in powder form and the workers mixed them with hydrogen peroxide to form a paste that was then applied to the hair. Seven patients in this series have been described in a previous study. ${ }^{1}$ Three other patients diagnosed with $\mathrm{OA}$ due to persulphate during the same period were not included in the study, since the SIC could not be performed: two had bronchial obstruction with $\mathrm{FEV}_{1}$ $<60 \%$ of the theoretical values, and one had a severe anaphylactic reaction when the prick test was performed.

Abbreviations: ERS, European Respiratory Society; $\mathrm{FEV}_{1}$, forced expiratory volume in the first second; NPV, negative predictive value; $\mathrm{OA}$, occupational asthma; PEF, peak expiratory flow; PPV, positive predictive value; $\mathrm{SE}$, sensitivity; SIC, specific inhalation challenge; $\mathrm{SP}$, specificity; TLV, threshold limit value 
Eight women (mean age 33 years; range $24-45$ years) with bronchial asthma who had never been exposed to persulphate salts, proceeding from our Pneumology Department outpatient asthma clinic, served as a control group (group B). Ten healthy female volunteers (mean age 34 years; range 2349 years) were also studied (group C).

Clinical history, chest $x$ ray, lung function testing, immunological testing, and specific inhalation challenge (SIC) were performed in all subjects. In group A, a peak flow study was carried out whenever possible. The project was approved by the Ethics Committee for Clinical Research of the hospital, and all the participating subjects provided their written informed consent.

\section{Lung function testing}

Spirometry was performed using a Datospir 200 (Sibel, Barcelona, Spain) according to European Respiratory Society (ERS) guidelines. ${ }^{16}$ The reference values used were those proposed by Roca and colleagues ${ }^{17}$ for the Mediterranean population. Bronchial challenge with methacholine was undertaken using the method described by Chai and colleague. ${ }^{18}$ Briefly, using a Mefar MB3 dosimeter (Ele $\mathrm{H} 2 \mathrm{O}$, Medically, Brescia, Italy), increasing doses of methacholine (range, 0.03 to $16 \mathrm{mg} / \mathrm{ml}$ ) were inhaled at three minute intervals until $\mathrm{FEV}_{1}$ had fallen by $20 \%$ of each baseline value or the subject had inhaled the maximum concentration of methacholine. The provocative concentration of methacholine causing a $20 \%$ fall in $\mathrm{FEV}_{1}$ (PC20) was expressed in $\mathrm{mg} / \mathrm{ml}$. The methacholine challenge test was considered negative when the PC20 was $>8 \mathrm{mg} / \mathrm{ml}$, in keeping with ERS guidelines. ${ }^{19}$ For the peak flow study, subjects were provided with mini Wright portable peak flow recorders (Clement Clarke International, United Kingdom) and diary cards, and were instructed in their use following the indications of Moscato and colleagues. ${ }^{20}$ Subjects were requested to record peak expiratory flow rates (PEF) at least four times a day for two weeks at work and two weeks off work. The recording was considered positive when the qualitative assessment revealed evident changes between the exposure periods.

\section{Immunological testing}

Skin prick tests to detect common inhalant allergens were performed according to the method described by Pepys. ${ }^{21} \mathrm{~A}$ skin prick test with potassium and ammonium persulphate (Sigma-Aldrich Corporation, St Louis, MO) was also performed in all subjects. This test was carried out using freshly produced 5\% (weight/volume) ammonium and potassium persulphate solutions. A phosphate buffered saline (PBS) solution was used as a solvent owing to the acidity of aqueous solutions. Histamine served as a positive control, and PBS solution served as a negative control. The results of the test were read at 15 minutes, and considered positive when the largest and smallest diameter of the wheal divided by 2 was $>3 \mathrm{~mm}$ and greater than that obtained with the negative control (PBS solution). ${ }^{22}$ The positive control (histamine) was $>3 \mathrm{~mm}$ in all patients. The total IgE level was also measured (UniCAP System; Pharmacia AB, Uppsala, Sweden) and a value of $>150 \mathrm{IU} / \mathrm{ml}$ was considered to be increased.

\section{Specific inhalation challenge}

Specific inhalation challenge with potassium persulphate was performed by the method proposed by Pepys and Hutchcroft ${ }^{23}$ for chemical agents and following the ERS guidelines. ${ }^{19}$ Subjects were admitted to the hospital for the duration of the test. In patients with OA due to persulphate salts, the challenge was carried out as previously described. ${ }^{1}$ Briefly, on the first day, $5 \mathrm{~g}$ potassium persulphate was mixed with
$150 \mathrm{~g}$ lactose and the patient tipped the mixture from one tray to another at a distance of $30 \mathrm{~cm}$ from the face in a $7 \mathrm{~m}^{3}$ challenge booth. The airtight booth had an independent air extraction system that could be regulated from the exterior, a methacrylate window to see inside, and an antechamber to avoid exposure of the staff to the agent tested. If the test proved negative, 10, 15, and $30 \mathrm{~g}$ of potassium persulphate mixed with $150 \mathrm{~g}$ lactose were then similarly tested on successive days. In subjects with asthma due to agents other than persulphate salts, the initial challenge consisted of $15 \mathrm{~g}$ of potassium persulphate with $150 \mathrm{~g}$ lactose, and in healthy subjects the test was performed with $30 \mathrm{~g}$ potassium persulphate and $150 \mathrm{~g}$ lactose. All subjects were challenged for 10 minutes unless respiratory symptoms developed before that time, in which case the challenge was stopped. Changes in pulmonary function were determined in all patients by measuring $\mathrm{FEV}_{1}$ and $\mathrm{FVC}$ at 10 minute intervals for the first hour and at hourly intervals thereafter. A response was considered positive when $\mathrm{FEV}_{1}$ fell by $>20 \%$ of the baseline value in the absence of any change in response to a control challenge of lactose powder alone, conducted on a separate day.

During the SIC we monitored the amount of powder the patient was exposed to by means of an automatic air sampler placed near the patient's face. The mean amount of powder collected was $35 \mathrm{mg} / \mathrm{m}^{3}$ and the proportion of persulphate in the mixtures ranged from $3 \%$ to $17 \%$. Thus, the estimated concentration of this substance in the air was between 1 and $6 \mathrm{mg} / \mathrm{m}^{3}$, according to the mixture used. Additionally, we studied the size of the particles generated using an aerodynamic particle sizer (APS 3320, TSI Particle Instruments, Inc., St Paul, MN) that took air samples during the test. The mean particle size obtained during the experiments was $17 \%<0.5 \mu \mathrm{m}, 63 \%$ between 1 and $5 \mu \mathrm{m}$, and $20 \%>10 \mu \mathrm{m}$.

Temperature and atmospheric pressure in the challenge booth during testing ranged from $19^{\circ} \mathrm{C}$ to $24^{\circ} \mathrm{C}$ and $746 \mathrm{~mm} \mathrm{Hg}$ to $755 \mathrm{~mm} \mathrm{Hg}$, respectively. Patients wore protective clothing and polyvinyl gloves during the test to avoid skin contact with the product. In keeping with ERS guidelines, anti-asthma treatment was suspended in all patients prior to performing both the SIC and methacholine tests. $^{19}$

\section{Statistical analysis}

The consistency of SIC to persulphate salts was estimated by evaluating sensitivity (SE) and specificity (SP) indices and positive (PPV) and negative (NPV) predictive values, with confidence intervals (CI) of 95\%. The Confidence Interval Analysis program was used to determine the CI, estimating the exact confidence limits of the proportion by applying the binomial formula. ${ }^{24}$ The Wilson method $^{25}$ was used to calculate the SE and SP indices. The Student's $t$ test was used to compare means.

\section{RESULTS}

\section{Clinical characteristics}

Table 1 shows clinical characteristics of the study population. In group A, three patients were smokers, five presented with rhinitis prior to developing asthma that was related to contact with persulphate salts, and four presented with dermatitis. Mean time of contact with persulphate salts prior to diagnosis was 11 years (range 3-25 years), and mean time elapsed between symptoms onset and diagnosis was 40 months (range 3-120 months).

In group B, none were smokers, three had rhinitis, and two dermatitis. All patients had mild intermittent asthma according to the GINA guidelines ${ }^{26}$ and were using $\beta_{2}$ adrenergic agonists on demand as the sole treatment. Mean 
Table 1 Clinical characteristics and results of diagnostic tests performed in the study populations

\begin{tabular}{|c|c|c|c|c|c|c|c|c|c|c|}
\hline & \multirow[b]{2}{*}{$\begin{array}{l}\text { Age } \\
\text { (y) }\end{array}$} & \multicolumn{3}{|c|}{ Clinical details } & \multicolumn{3}{|c|}{ Lung function tests } & \multicolumn{3}{|c|}{ Immunological tests } \\
\hline & & $\begin{array}{l}\text { Smoking } \\
\text { history }\end{array}$ & Rhinitis† & Dermatitis† & $\begin{array}{l}\text { FEV }_{1} \\
\text { (I) }\end{array}$ & $\begin{array}{l}\text { FEV } 1 \\
(\%)\end{array}$ & $\begin{array}{l}\text { PC20 } \\
\text { (mg/ml) }\end{array}$ & $\begin{array}{l}\lg E \\
(\mathrm{kU} / \mathrm{l})\end{array}$ & SPTIA* & SPTPS $\tau^{*}$ \\
\hline \multicolumn{11}{|c|}{ Patients with OA due to persulphate salts } \\
\hline 1 & 46 & No & Yes & No & 2.68 & 99 & 0.36 & 182 & + & $-/-$ \\
\hline 2 & 43 & No & No & No & 1.87 & 79 & 0.06 & 203 & - & $-1-$ \\
\hline 3 & 23 & Yes & No & No & 3.02 & 92 & 0.18 & 1295 & - & $-1-$ \\
\hline 4 & 44 & No & Yes & No & 2.62 & 98 & $>8$ & 25 & - & $+/+$ \\
\hline 5 & 24 & Yes & Yes & Yes & 3.45 & 105 & 0.06 & 509 & - & $+/+$ \\
\hline 6 & 32 & No & Yes & Yes & 3.47 & 108 & 1.89 & 342 & + & $+/+$ \\
\hline 7 & 25 & Yes & Yes & Yes & 3.85 & 106 & 6.50 & 541 & + & $+/+$ \\
\hline 8 & 52 & No & No & Yes & 2.41 & 99 & $>8$ & 17 & - & $-1-$ \\
\hline \multicolumn{11}{|c|}{ Asthmatic control group } \\
\hline 1 & 32 & No & No & No & 2.89 & 93 & 1.92 & 46 & + & $-/-$ \\
\hline 2 & 32 & No & Yes & Yes & 2.76 & 90 & 0.82 & 299 & + & $-1-$ \\
\hline 3 & 42 & No & No & No & 3.29 & 89 & 1.00 & 30 & + & $-1-$ \\
\hline 4 & 32 & No & No & No & 3.39 & 109 & $>8$ & 309 & + & $-1-$ \\
\hline 5 & 45 & No & No & No & 2.33 & 100 & 0.06 & 82 & + & $-1-$ \\
\hline 6 & 30 & No & No & No & 2.81 & 82 & 0.06 & 1200 & + & $-1-$ \\
\hline 7 & 24 & No & Yes & Yes & 3.64 & 106 & 6.20 & 405 & + & $-1-$ \\
\hline 8 & 27 & No & Yes & No & 3.61 & 92 & 7.20 & 42 & + & $-1-$ \\
\hline \multicolumn{11}{|c|}{ Healthy individuals } \\
\hline 1 & 34 & No & No & No & 3.13 & 107 & $>8$ & 17 & + & $-/-$ \\
\hline 2 & 28 & No & No & No & 3.91 & 112 & $>8$ & 35 & + & $-1-$ \\
\hline 3 & 27 & No & No & No & 3.05 & 89 & $>8$ & 34 & - & $-1-$ \\
\hline 4 & 49 & Yes & No & No & 2.83 & 102 & $>8$ & 23 & - & $-1-$ \\
\hline 5 & 28 & Yes & No & No & 3.13 & 101 & $>8$ & 30 & - & $-1-$ \\
\hline 6 & 46 & No & No & No & 2.57 & 85 & $>8$ & 21 & - & $-1-$ \\
\hline 7 & 33 & No & No & No & 2.54 & 94 & $>8$ & 122 & + & $-1-$ \\
\hline 8 & 23 & No & No & No & 2.71 & 80 & $>8$ & 10 & - & $-1-$ \\
\hline 9 & 32 & No & No & No & 3.15 & 105 & $>8$ & 10 & - & $-1-$ \\
\hline 10 & 39 & No & No & No & 3.61 & 119 & $>8$ & 10 & - & $-1-$ \\
\hline & $\mathrm{r}$ & contact & sulphat & 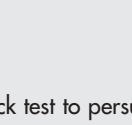 & 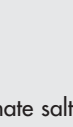 & & & & & \\
\hline
\end{tabular}

evolution time of the asthma was 10 years (range $1-20$ years). In group $\mathrm{C}$, two were smokers and none had rhinitis or dermatitis.

\section{Lung function testing}

Table 1 shows the results of spirometry and methacholine testing. All subjects had normal spirometry findings at the time of the study. Methacholine tests were positive in six patients from group A and seven from group B. All healthy women in group $\mathrm{C}$ had negative methacholine results. Mean (SD) PC20 was $1.50(2.54) \mathrm{mg} / \mathrm{ml}$ in Group A and 2.50 (2.97) $\mathrm{mg} / \mathrm{ml}$ in group B. No significant differences were found between groups $(p=0.526)$. Peak expiratory flow testing was performed in five patients from group A and was consistent with occupational asthma in four cases. This test could not be performed in three patients since they were no longer working in their professions at the time of the study.

\section{Immunological tests}

Skin prick tests to persulphate salts were positive in four patients from group $\mathrm{A}$ and negative in all subjects from groups $\mathrm{B}$ and $\mathrm{C}$ (table 1). Skin prick tests to common aeroallergens were positive in three patients from group A, all patients from group B, and three healthy women from group C (table 1). Total IgE values proved to be high in six patients from group A and four from Group B (table 1).

\section{Specific inhalation challenge}

Specific inhalation challenge was positive in all patients from group A, eliciting an early response in one patient, a late response in six patients, and a dual response in one patient (fig 1). The test proved positive at a dose of $5 \mathrm{~g}$ of potassium persulphate in one patient, $10 \mathrm{~g}$ in three patients, $15 \mathrm{~g}$ in one patient, and $30 \mathrm{~g}$ in the remaining three.

The test was also positive in one patient from group B, eliciting a late response (fig 2) at a dose of $30 \mathrm{~g}$ of potassium persulphate. Specific inhalation challenge was negative in all the healthy women from group C.

Table 2 shows the indices of sensitivity and specificity, positive and negative predictive values, and 95\% confidence intervals resulting from comparisons between groups A and B.

\section{DISCUSSION}

This study describes a useful method for performing SIC to diagnose occupational asthma secondary to inhalation of persulphate salts. The method permits the establishment of dose-response relations and presents acceptable sensitivity and specificity.

Specific inhalation challenge is considered the "gold standard" test for the diagnosis of occupational asthma and identification of the possible causal agents of the disease. ${ }^{27}$ Unlike non-specific bronchial challenge tests, for which validated and standardised methods exist, ${ }^{18} 28$ the methodology for performing SIC is not yet well established. Exposure to the suspected agent can be carried out by various methods, depending on the nature of the substance and according to the facilities in each lung function laboratory. ${ }^{29}$ Despite its being the reference test, false negatives can occur when SIC is conducted with an erroneous agent, when exposure to the agent is insufficient, or when the worker has avoided exposure for a prolonged period of time. ${ }^{27}$ In addition, false positives can arise when the asthma is unstable or when exposure to the agent is made at an irritant dose. ${ }^{27}$ These 

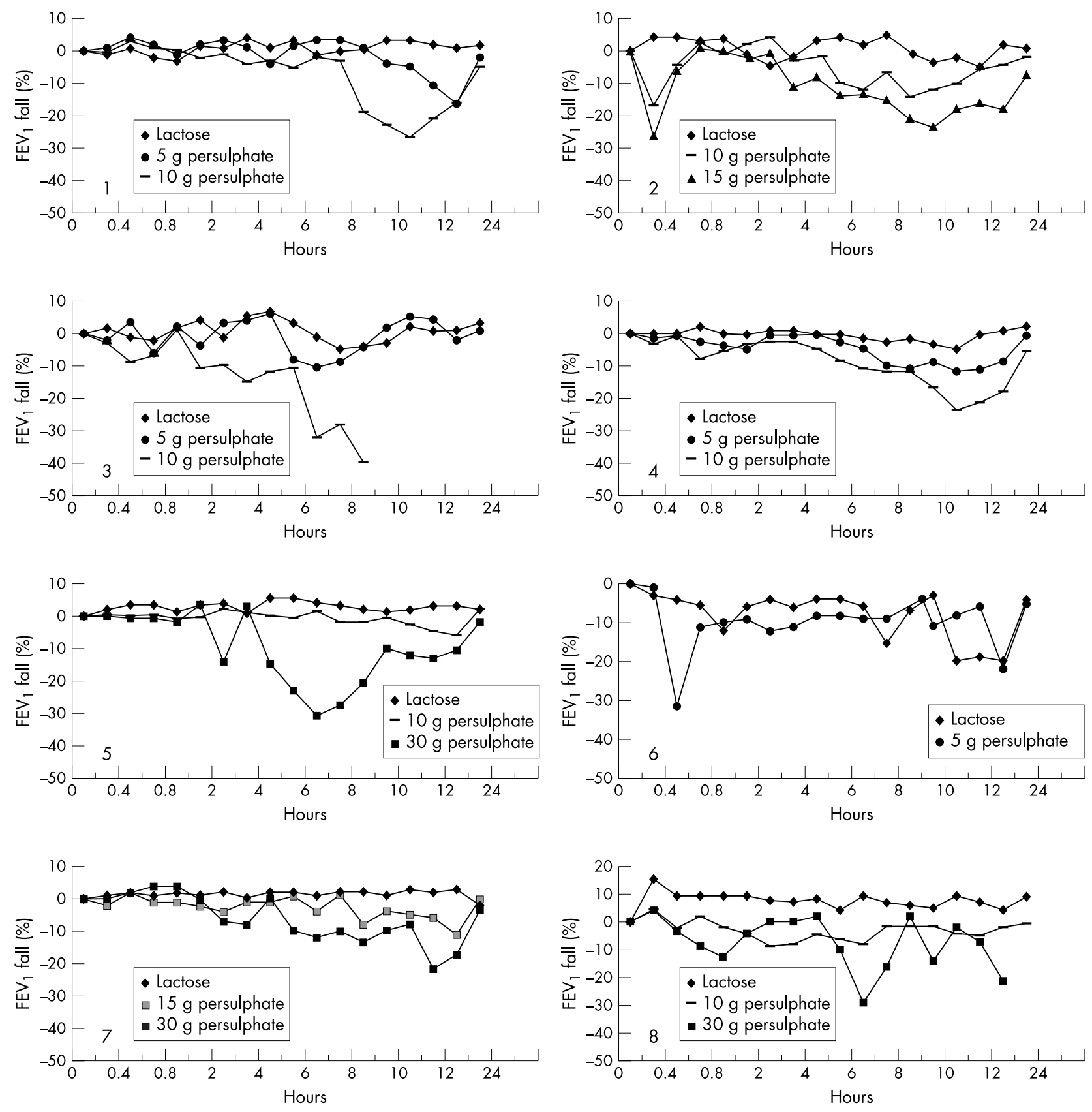

Figure 1 Bronchial response to SIC with potassium persulphate in patients with OA due to persulphate salts.

observations underline the importance of standardising the SIC method for each of the substances or products causing $\mathrm{OA}$, including control subjects to enable determination of the sensitivity and specificity of the method. To our knowledge, these indices have been assessed only for SIC with isocyanates. ${ }^{3031}$

In the specific case of OA due to persulphate salts, different methods have been used for performing SIC. Some authors have devised tests that simulate the exposure occurring at the workplace, in which the patient mixes bleach powder with hydrogen peroxide to a paste in a mortar. ${ }^{45}$ In the method used by Blainey et al, $30 \mathrm{~g}$ of bleach powder was mixed with $50 \mathrm{~g}$ of lactose, and the subjects tipped the mixture from one tray to another $30 \mathrm{~cm}$ away from the face for 10 minutes in a challenge chamber with an independent air extraction system. ${ }^{2}$ Parra et al exposed the patient for two minutes to an aerosolised extract of non-dialysed ammonium persulphate at a final concentration of $1 / 50 \mathrm{w} / \mathrm{v},{ }^{11}$ and Macchioni et al had the patient breathe through an oronasal mask connected to a small Plexiglas cabin containing a suspension of bleach powder mixed with lactose. ${ }^{13}$ Whatever the method used, to ensure the diagnosis of asthma due to persulphate salts, the possibility of false positive results should be minimised, bearing in mind that persulphate salts can cause symptoms through an irritative mechanism. ${ }^{5}$ The tests were performed in control subjects to investigate this possibility in only two of the above mentioned studies, ${ }^{211}$ although no data of sensitivity and specificity were presented, probably because of the small number of individuals included.

The method for performing SIC in the present study is similar to that proposed by Blainey and colleagues ${ }^{2}$ with some modifications, including the use of potassium persulphate instead of bleach powder and the gradual increase in 


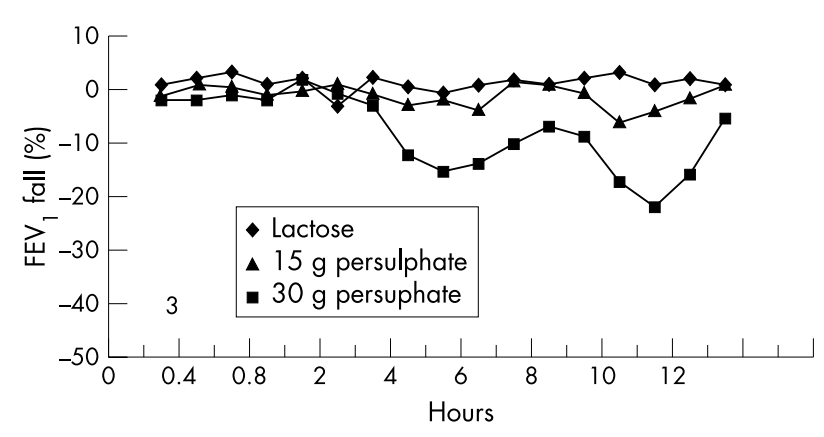

Figure 2 Bronchial response to $\mathrm{SIC}$ with potassium persulphate in the group B patient testing positive.

the exposure dose. Since other substances present in bleach powder, such as ammonium chloride, sodium silicate, sodium metasilicate, EDTA, or silica could elicit a positive response to the test through non-specific irritative mechanisms, ${ }^{32}$ the use of potassium persulphate permits the establishment of a specific diagnosis for this substance. By performing the test with increasing doses of potassium persulphate, severe adverse reactions such as bronchospasm are minimised, and highly useful dose-response relations can be established.

To our knowledge, previous works investigating the SIC with persulphate salts did not include air measurements of the substance during the challenge. In the present study, persulphate air levels generated during the SIC ranged between 1 and $6 \mathrm{mg} / \mathrm{m}^{3}$, according to the concentration in the mixture used. These concentrations exceed the threshold limit value (TLV) $\left(0.1 \mathrm{mg} / \mathrm{m}^{3}\right)$. Nevertheless, the single study that measured air levels of persulphates at the workplace showed that concentrations below $1 \mathrm{mg} / \mathrm{m}^{3}$ were not associated with occupational asthma. ${ }^{33}$ Taking this into account, it is reasonable to assume that the test would have very low sensitivity if it were performed with concentrations below the TLV. In fact, the test was positive in only one of our patients at a concentration of $5 \mathrm{~g}$ persulphate/ $150 \mathrm{~g}$ of lactose, the equivalent of an air level of approximately $1 \mathrm{mg} / \mathrm{m}^{3}$ of persulphate. The indices of sensitivity and specificity of the method, obtained by comparing the series of eight persulphate salt induced asthma patients with a control group of bronchial asthma patients never exposed to persulphate salts and having a similar degree of bronchial hyperresponse (table 1), showed that the method is adequate for diagnosing the disease.

In the present study, all the patients with asthma due to persulphate salts presented a positive challenge test: an early response was observed in one case, a dual response in another, and a late response in six. Only one patient with bronchial asthma who had never been exposed to persulphate salts tested positive, with a fall in $\mathrm{FEV}_{1}$ first manifested at eight hours post-inhalation. The fact that this patient showed a late response raises the possibility that the positive result may have been due to personal factors related to the patient, such as poor asthma control secondary to temporary withdrawal of medication during the study. If the positive result had been due to an irritative mechanism resulting from the dose inhaled, an early, not late, response, more typical of agents causing asthma through an immunological mechanism, would have been expected. ${ }^{27}$

The availability of a validated method for performing SIC in these patients is particularly important since recent studies point to this entity as one of the most frequent causes of occupational asthma. ${ }^{64}{ }^{35}$ Furthermore, the other available tests for reaching a diagnosis are not conclusive. ${ }^{12} 78$ In fact, in this series, specific skin tests showed a sensitivity of only
Table 2 SIC sensitivity and specificity when patients with OA due to persulphate salts (group A) were compared with asthmatic patients never exposed to persulphate salts (group B) (A/B)

\begin{tabular}{lc}
\hline & A/B \\
\hline Sensitivity & $100(67.6-100)$ \\
Specificity & $87.5(52.9-97.8)$ \\
PPV & $88.9(56.5-98.0)$ \\
NPV & $100(64.6-100)$ \\
\hline
\end{tabular}

Results expressed as \% (95\% Cl).

PPV, positive predictive value; NPV, negative predictive value.

$50 \%$. Moreover, a positive immunological test shows sensitisation to the agent, but does not necessarily imply development of the disease. ${ }^{36}$ Nevertheless, SIC is considered absolutely contraindicated when the patient has severe obstruction, a history of myocardial infarction or recent cerebrovascular accident ( $<3$ months), arterial aneurysm, or inability to understand the test. ${ }^{27}$ Contraindications were present in three of our patients diagnosed with persulphate induced asthma in whom the test could not be performed and who could not be included in the study.

In conclusion, specific tests such as SIC are required for the diagnosis of occupational asthma due to persulphate salts. Specific inhalation challenge permits identification of the causal agent and precise aetiological diagnosis. The procedure described in this study allows patients with bronchial asthma to be distinguished from those with persulphate salt induced OA. Validation of SIC by the procedure followed contributes greatly to clinical practice since it is a safe method providing early diagnosis of the disease, thereby reducing exposure time to the causal agent and improving the prognosis of the patient.

\section{ACKNOWLEDGEMENTS}

The authors are grateful to Celine Cavallo for the English editing of the article, to Teresa Codinach, a member of the nursing staff, and to Rosa Lloria for editorial assistance.

\section{Authors' affiliations}

X Muñoz, Servicio de Neumología, Hospital Vall d'Hebron, Departamento de Biología Celular, Fisiología e Immunología, Facultad de Medicina, Universidad Autonoma de Barcelona, Barcelona, Spain M J Cruz, R Orriols, M Espuga, F Morell, Servicio de Neumología, Hospital Vall d'Hebron, Barcelona, Spain

F Torres, Laboratorio de Bioestadistica y Epidemiología, Universidad Autonoma de Barcelona, Barcelona, Spain

This study was financed in part by RedRespira-ISCiii-RTIC-03/11 and FUCAP

\section{REFERENCES}

1 Muñoz X, Cruz MJ, Orriols R, et al. Occupational asthma due to persulfate salts. Chest 2003;123:2122-7.

2 Blainey AD, Ollier S, Cundell D, et al. Occupational asthma in a hairdressing salon. Thorax 1986;41:42-50.

3 Gaultier M, Gervais P, Mellerio F. Deux causes d'asthme professionel chez les coiffeurs: persulphate et soie. Arch Mal Prof 1966;27:809-13.

4 Pepys J, Hutchcroft BJ, Breslin ABX. Asthma due to inhaled chemical agentspersulphate salts and henna in hairdressers. Clin Allergy 1976;6:399-404.

5 Baur X, Fruhmann G, Liebe VV. Occupational asthma and dermatitis after exposure to dust of persulphate salts in two industrial workers. Respiration 1979;38: 144-50.

6 Kopferschmitt-Kubler MC, Ameille J, Popin E, et al. Occupational asthma in France: a 1-yr report of the Observatoire National de Asthmes Professionnels project. Eur Respir J 2002;19:84-9.

7 Malo JL, Ghezzo H, L'Archevêque J, et al. Is the clinical history a satisfactory means of diagnosing occupational asthma? Am Rev Respir Dis $1991 ; 143: 528-32$.

8 Wrbitzky R, Drexler H, Letzel S. Early reaction type allergies and diseases of the respiratory passages in employees from persulphate production. Int Arch Occup Environ Health 1995;67:413-17. 
9 Starr JC, Yunginger J, Brahser GW. Immediate type I asthmatic response to henna following occupational exposure in hairdressers. Ann Allergy 1982;48:98-9.

10 Gelfand $\mathrm{HH}$. Respiratory allergy due to chemical compounds encountered in the rubber, lacquer, shellac, and beauty culture industries. J Allergy 1963;34:374-81

11 Parra FM, Igea JM, Quirce S, et al. Occupational asthma in a hairdresser caused by persulphate salts. Allergy 1992;47:656-60.

12 Gamboa PM Cuesta GC Garcia BE, et al. Late asthmatic reaction in a hairdresser, due to the inhalation of ammonium persulphate salts. Allergol immunopathol 1989;17:109-11.

13 Macchioni P, Kotopoulos C, Talini D, et al. Asthma in hairdressers: a report of 5 cases. Med Lav 1999;90:776-85.

14 Yawalkar N, Helbling A, Pichler CE, et al. T cell involvement in persulphate triggered occupational contact dermatitis and asthma. Ann Allergy Asthma Immunol 1999;82:401-4.

15 Chan-Yeung M, Malo JL. Occupational asthma. N Engl J Med 1995;333:107-12

16 Quanjer PH, Tammeling GJ, Cotes JE, et al. Lung volumes and forced ventilatory flows. Eur Respir J 1993;6(suppl):5-40.

17 Roca J, Sanchis J, Agustí-Vidal A, et al. Spirometric reference values from a Mediterranean population. Bull Eur Physiopathol Respir 1986;22:217-24.

18 Chai H, Farr R, Froehlich LA, et al. Standardization of bronchial inhalation challenge procedures. J Allergy Clin Immunol 1975;56:323-7.

19 Sterk PJ, Fabbri LM, Quanjer PhH, et al. Airway responsiveness. Standardized challenge testing with pharmacological, physical and sensitizing stimuli in adults. Eur Respir J 1993:6(suppl):53-83.

20 Moscato G, Godnic-Cvar J, Maestrelli P, et al. Statement on self-monitoring of peak expiratory flows in the investigation of occupational asthma. Eur Respir J 1995;8:1605-10.

21 Pepys J. Skin test in diagnosis. In: Gell PGH, Coombes RRA, Lachman PJ, eds. Clinical aspects of immunology, 3rd edn. Oxford, UK: Blackwell Scientific Publications, 1975:55-80.

22 Morell F, Codina R, Rodrigo MJ, et al. Increased positivity of skin test and allergenic stability of glycerinated soybean hull extracts. Clin Exp Allergy 1999;29:388-93.

23 Pepys J, Hutchcroft BJ. Bronchial provocation test in aetiology diagnosis and analysis of asthma. Am Rev Respir Dis 1975;112:829-59.
24 Gardner MJ, Gardner SB, Winter PD. Confidence interval analysis. London: BMJ Publications, 1989

25 Argimón Pallás JM, Jiménez Villa J. Métodos de investigación. Barcelona: Ediciones Doyma SA, 1991:223-7.

26 Global Initiative for Asthma. Global strategy for asthma management and prevention. NHLBI/WHO workshop report, NIH Publication no.963659B. National Institute of Health, National Heart Lung and Blood Institute, 1998.

27 Cartier A, Malo JL. Occupational challenge test. In: Bernstein IL, ChanYeung M, Malo JL, Bernstein D, eds. Asthma in the workplace, 2nd edn. New York: Marcel Dekker Inc, 1999:211-33.

28 Cockroft DW, Killian DM, Mellon JA, et al. Bronchial reactivity to inhaled histamine: a method and clinical survey. Clin Allergy 1977;7:235-43.

29 Cartier A, Chairman MD, Bernstein IL, et al. Guidelines for bronchoprovocation on the investigation of occupational asthma. J Allergy Clin Immunol, 1989;84(5 pt 2) 823-919..

30 Tossin L, Chiesura-Corona P, Fabri LM, et al. Ketotifen does not inhibit asthmatic reactions induced by toluene-diisocyanate in sensitised subjects. Clin Exp Allergy 1989;19:177-82.

31 Mapp LE, Di Giacomo R, Broseghini C, et al. Late, but not early, asthmatic reactions induced by toluene diisocyanate (TDI) are associated with increased airway responsiveness. Eur J Respir Dis 1986;69:276-84.

32 Weir DC, Robertson AS, Jones S, et al. Occupational asthma due to soft corrosive soldering fluxes containing zinc chloride and ammonium chloride. Thorax 1989;44:220-3.

33 Merget R, Buenemann A, Kulzer R, et al. A cross sectional study of chemical industry workers with occupational exposure to persulphates. Occup Environ Med 1996;53:422-6.

34 Kogevinas M, Anto JM, Soriano J, and the Spanish Group of the European Asthma Study, et al. The risk of asthma attributable to occupational exposures. A population-based study in Spain. Am J Respir Crit Care Med $1996 ; 154: 137-43$

35 Cullinan P, Newman Taylor AJ. Aetiology of occupational asthma. Clin Exp Allergy 1997;27(suppl 1):41-6.

36 Wrbitzky R, Drexler H, Letzel S. Early reaction type allergies and diseases of the respiratory passages in employees from persulphate production. Int Arch Occup Environ Health 1995;67:413-17. 